\title{
UM BREVE TESTEMUNHO: QUASE DUAS DÉCADAS COM RITA SCHMIDT
}

\author{
Anselmo Peres Alós \\ Universidade Federal de Santa Maria, UFSM, Santa Maria, RS, Brasil \\ I am the struggle with the sword in my hands, \\ and I don't intend to run until you run me \\ (Zora Nearle Huston, Dust Tracks on a Road, 1942).
}

Rita Terezinha Schmidt possui uma trajetória invejável dentro e fora da UFRGS. Foi Vice-Diretora do Instituto de Letras, entre 1993 e 1997. Foi Coordenadora do Programa de Pós-Graduação em Letras da UFRGS, entre 2000 e 2002. Foi integrante da Câmara de Pesquisa da UFRGS, de 1998 a 2000. Foi Vice-Presidente da ABRALIC, no período de 2002 a 2004. Escreveu, ao longo de seu doutorado, realizado na Universidade de Pittsburg, nos Estados Unidos, a primeira tese a dar conta da totalidade da obra narrativa da afro-estadunidense Zora Nearle Huston (tese até hoje inédita em Língua Portuguesa). É, desde 2013, Diretora do Instituto Confúcio da UFRGS, responsável por convênios e projetos de integração universitária de natureza interdisciplinar entre o Brasil e a China. Isso apenas para dar um breve panorama da sua atuação, para além das atividades de docência e de pesquisa que realiza sistematicamente na UFRGS. Mas não é apenas em função de sua vida nos meandros burocráticos da Universidade que Rita Terezinha Schmidt se faz marcante. Ela foi (ainda é e será por muito tempo) uma presença constante ao longo da minha vida intelectual.

Lembro-me, ainda hoje, quando eu, lá pela metade de 1998, do alto de toda a empáfia, a ingenuidade e a insegurança que caracterizam um estudante de Letras de 19 anos de idade, fui bater à porta do gabinete dela, buscando orientação. Eu queria discutir questôes envolvendo sexualidade na obra de Caio Fernando Abreu e, embora ainda não tivesse claro na minha mente exatamente qual era o perfil intelectual de Rita, sabia já da longa história dela como pesquisadora no campo do comparatismo, da teoria e crítica feminista, e da Literatura Brasileira de autoria feminina. Eu havia passado a semana anterior lendo, sublinhando, resenhando e fichando com toda a dedicação que me era possível naquele momento a coletânea Tendências e impasses: o feminismo como crítica da cultura ${ }^{1}$, a famosa coletânea de ensaios sobre teoria e crítica feminista organizada por Heloísa

\footnotetext{
${ }^{1}$ Rio de Janeiro: Rocco, 1994.
} 
Buarque de Hollanda, único trabalho de teoria e crítica feminista do qual eu já havia ouvido falar naquelas alturas. Lembro que saí do gabinete depois de aproximadamente uma hora de conversa: corri para uma das mesas da cantina do campus, tentando rascunhar de memória cada detalhe do que havíamos conversado. Acho que não deve ter restado fiapo de lembrança desse primeiro encontro nas memórias de Rita, mas eu recordo fotograficamente de cada detalhe. Foi nesse encontro que minha vida intelectual efetivamente começou.

Saí do gabinete de Rita Schmidt (se a memória não me trai, era a sala 222, no segundo andar do Instituto de Letras da UFRGS) com uma bagagem bastante significativa (o fato de ela ter me emprestado dois dos volumes de sua biblioteca de trabalho teve um peso imenso em minha autoestima - nunca nenhum docente da universidade havia me emprestado um livro de sua própria biblioteca). Falodo romance Úrsula ${ }^{2}$, de Maria Firmina dos Reis, da coletânea The New Feminist Criticism ${ }^{3}$, organizada por Elaine Showalter (muitos anos depois, confessei a Rita que minha proficiência de leitura em Língua Inglesa era - naquele momento - mínima, detalhe que convenientemente ocultei ao longo de nossa conversa), e do mais importante de tudo: um convite para assistir como ouvinte ao curso $A$ literatura brasileira de autoria feminina, disciplina que ela ofereceria no PPGLetras da UFRGS ao longo do segundo semestre de 1998. Li, aos trancos e barrancos, os artigos da coletânea de Showalter. Com muita dificuldade, com três dicionários ao meu lado (um bilíngue, Português/Inglês - acredito que fosse o Michaelis -, mais o Oxford Dictionary for Advanced Lerners e o Dicionário Aurélio da Língua Portuguesa), percorri os textos assinados por Elaine Showalter, Barbara Smith, Hélène Cixous, Luce Irigaray, Susan Gubar e Sandra Gilbert. Li três vezes seguidas o romance Úrsula, mas não conseguia me concentrar no enredo, tal o impacto do capítulo intitulado "Mãe Susana". Uma semana depois, voltei ao gabinete de Rita, devolvi os livros e assumi o compromisso de acompanhar como aluno-ouvinte a disciplina que ela ofereceria no PPG-Letras.

Essa experiência marcou profundamente minha percepção sobre o que a Literatura é e sobre o que ela pode fazer. Dei-me conta das profundas lacunas que as aulas de Literatura Brasileira que eu cursava na graduação apresentavam. Cabe lembrar que uma parte considerável da minha geração estava lendo Lima Barreto, Machado de Assis e Cruz e Sousa sem levar em consideração a importância de seu pertencimento étnico-racial, e que

2 4. ed. Florianópolis: Mulheres, 2004.

${ }^{3}$ New York: Panteon Books, 1985. 
essa mesma geração de estudantes de Letras via em Rachel de Queirós e Clarice Lispector as primeiras escritoras da história da narrativa brasileira. O curso ministrado por Rita centrava-se no romance e elencava como leituras obrigatórias uma série de obras sobre as quais eu ouvia falar pela primeira vez, à exceção de Úrsula. Li Júlia Lopes de Almeida (A Silveirinha ${ }^{4}$ ), li Patrícia Galvão (Parque industrial ${ }^{5}$ ), li Helena Parente Cunha (As doze cores do vermelho ${ }^{6}$ ), li Nélida Piñon (Fundador ${ }^{\top}$ ). Ao longo das aulas, tive meus primeiros contatos com textos críticos assinados pela própria Rita Schmidt, por Constância Lima Duarte, e por Zahidé Lupinacci Muzart. Fui apresentado a outros trabalhos de Heloísa Buarque de Hollanda. E ouvi, pela primeira vez, referência aos trabalhos de Homi Bhabha, Jonathan Culler, Gayatri Chakravorty Spivak e David Harvey. Entre as alunas presentes nas aulas - ao que me lembro, eu era o único homem presente no curso - conheci Rosane Saint-Dennis Salomoni (que se tornou uma grande especialista na obra de Júlia Lopes de Almeida), Conceição Beltrão (psicóloga e analista junguiana que escreveu uma belíssima tese sobre a questão alquímica na obra de Clarice Lispector) e Andrea do Roccio Souto, que cruzou mais algumas vezes seus caminhos com os meus, e hoje divide comigo a sala 3233-B, no terceiro andar do Prédio 16, na Universidade Federal de Santa Maria.

Perdi o contato com Rita ao longo de 1999 e reencontrei-a apenas ao final desse mesmo ano: ela estava selecionando bolsistas de iniciação científica. Cheguei, uma vez mais, um tanto inseguro, com cópias de alguns trabalhos monográficos de fim de disciplina que eu havia escrito. Fui selecionado e, sob sua orientaçáo, ao longo dos anos 2000 e 2001, escrevi meus primeiros artigos, que tomavam como objeto os romances $\mathbf{D}$. Narcisa de Villar (de Ana Luísa de Azevedo Castro ${ }^{8}$ ) e A rainha do Ignoto (de Emília Freitas $\left.{ }^{9}\right)$. Nas tardes de sexta-feira, discutíamos os romances escritos pelas mulheres do século XIX, os princípios da teoria e da crítica feminista, bem como o debate "estudos culturais vs. literatura comparada", washback das contendas intelectuais de finais da década de 1990. Àquela época, já havia sido publicado o primeiro volume da antologia Escritoras brasileiras

\footnotetext{
${ }^{4}$ Florianópolis: Mulheres, 1997.

${ }^{5}$ Porto Alegre: Mercado Aberto, 1994.

${ }^{6}$ 2. ed. Rio de Janeiro, Tempo Brasileiro, 1998.

${ }^{7}$ Rio de Janeiro: José Álvaro Editor, 1969.

8 2. ed. Florianópolis: Semprelo, 1990.

9 2. ed. Fortaleza: Imprensa Oficial do Ceará, 1980.
} 
do século XIX $^{10}$, na qual Rita assinava inúmeros ensaios sobre escritoras oitocentistas sul-rio-grandenses. Em tempos nos quais o acesso à internet era um luxo consideravelmente caro para um estudante de graduaçáo, auxiliei na pesquisa que Rita desenvolvia na época, fazendo coleta e levantamento de material bibliográfico em importantes acervos de Porto Alegre - Biblioteca Central da UFRGS, Biblioteca Pública de Porto Alegre e Instituto Histórico e Geográfico do RS, entre outros acervos - para os dois ensaios que minha orientadora estava escrevendo (sobre Ana Vasconcelos César e sobre Andradina América Andrade de Oliveira) para o segundo volume de Escritoras brasileiras do século XIX ${ }^{11}$.

Após nossas reuniôes, não raro, encerrávamos a discussão tomando café no subsolo do Prédio de Aulas das Ciências Humanas do Campus do Vale da UFRGS, no Bar do Antônio. Nessas conversas, falávamos de política, de amenidades e de projetos para o futuro. Foi em uma dessas conversas que ela me recomendou a leitura de Gender Trouble, de Judith Butler ${ }^{12}$, filósofa estadunidense que foi fundamental para o desenvolvimento da minha pesquisa de doutorado, defendida em 2007, e que, alguns anos depois, se transformou em meu primeiro livro publicado ${ }^{13}$. Minha parceria intelectual com Rita, na condiçấo de orientando, foi-se estendendo ao longo dos anos. De ouvinte de suas aulas, passei a bolsista de iniciação científica, posição na qual permaneci por dois anos. Ingressei no mestrado em 2002, também sob sua orientação. Em 2004, ingressei no doutorado, também sob sua orientação. Ao longo desse tempo, entretanto, nossa relação extrapolou, em muito, os limites por vezes rígidos e hierárquicos que caracterizam a relação orientador/orientando dentro dos muros da universidade. Já na iniciação científica, Rita sempre tratava, a mim e aos outros orientandos "sob suas asas", com um profundo senso de respeito intelectual. Ela sempre se mostrou, ademais de uma docente e orientadora extremamente competente, uma intelectual disposta a assumir uma posição de escuta frente seus orientandos, quer fosse mestrandos, doutorandos ou estudantes de graduação.

Essa posição de escuta, acredito, foi fundamental para forjar o perfil profissional e humano dos orientandos que passaram pelas mãos de Rita Schmidt. O papel de Rita na formação de recursos humanos, docentes

\footnotetext{
${ }^{10}$ Organização de Zahidé Muzart. Florianópolis/Santa Cruz do Sul: Mulheres/Edunisc, 1999.

${ }^{11}$ Organização de Zahidé Muzart. Florianópolis/Santa Cruz do Sul: Mulheres/Edunisc, 2002.

${ }^{12}$ London: Routledge, 1990.

${ }^{13}$ A letra, o corpo e o desejo: masculinidades subversivas no romance latino-americano. Florianópolis: Mulheres, 2013.
} 
e pesquisadores na área dos Estudos Literários é digna de nota. Gostaria de mencionar aqui os nomes de Eliane Amaral Campello (professora da PUC-Pelotas), Vera Lucia Lenz Vianna da Silva (professora da UFSM), Rosalia Neumann Garcia (professora da UFRGS), Marcos Machado Nunes (professor da Universidade de Bochum, na Alemanha), Eni de Paiva Celidonio (professora da UFSM), Salete Rosa Pezzi dos Santos (professora da Universidade de Caxias do Sul), Marta Ramos Oliveira (professora da UFRGS), Ricardo Araújo Barberena (professor da PUC-RS), Wilson Julián Aldana Nieto (professor da Fundación Universitaria Monserrate, em Bogotá), Jorge Alberto Reichert (professor da UNIVATES), Flávia Adriane Andrade (professora do IFRS), Andrei dos Santos Cunha (professor da UFRGS), Rafael Eisinger Guimarães (professor da UNISC), Paulo Henrique Pressoto (professor da UEMS) e Cíntia Schwantes (professora da UnB), apenas para ficar em alguns nomes daqueles que passaram pela orientação de Rita em seus respectivos doutorados.

Para aquele que se depara com esse imenso legado humano pela primeira vez e pensa na intelectual responsável pela formação de um grupo de pesquisadores de ponta como o que mencionei algumas linhas acima, é muito tentador esboçar um perfil de profissional sisuda, rígida e severa. Nada pode ser mais falso para descrever Rita Schmidt. Ela é, sim, uma pesquisadora extremamente metódica e cuidadosa e faz valer suas origens germânicas no rigor da disciplina que aplica a si mesma, ao seu trabalho intelectual e àquilo que cobra em termos de performance acadêmica de seus orientandos. Mas ela é, antes de tudo, uma mulher extremamente gentil, atenciosa, generosa - e acredito que aqui falo por todos seus orientandos, sejam os de ontem, sejamos de hoje. Inúmeras foram as vezes que ela abriu aos seus alunos as portas de sua casa, de sua biblioteca e de seu coraçáo. São memoráveis os encontros que ela promoveu nas dependências de sua casa para socializar com seus alunos, orientandos e colegas do Instituto de Letras. Tenho agradabilíssimas memórias dos jantares e happy-hours que ela ofereceu, regados a bons vinhos, boa cerveja e muita música. São poucos os que sabem disso, mas ela tem um sistema de luz e um globo de espelhos giratório instalados no teto de seu living room e seus jantares inevitavelmente terminam com uma sessão discothèque, embalada pelo som da década de 1970. Ela tem um jardim com uma concepção estética singular (para dizer o mínimo) nos fundos de sua residência, no entorno da piscina, onde não raro recebe seus colegas e orientandos nas noites quentes do verão portoalegrense. De vez em quando, muito raramente, e, embora não fume, ela acende um cigarro filado (por vezes do meu maço, quando nos encontramos, por vezes do maço do seu filho, o Renan - mas só às vezes, pois ela afirmará 
que não fuma, mesmo sob tortura), serve uma dose dupla de whisky e escuta a voz rouca de Billie Holiday, pensando sabe-se lá sobre o quê, silenciosa e enigmática, antes de se fechar em copas e se recolher aos seus aposentos.

Minha convivência com Rita Schmidt estende-se por quase duas décadas. Ela acompanhou minhas crises de destempero, de brancos e de vazios criativos ao longo dos anos que dediquei à minha formação. Ela sempre esteve presente, disposta a ouvir e a interferir no meu processo de escrita, nos rumos das minhas decisões nem sempre sensatas sobre minha vida profissional. Devo a essa convivência com ela todos os méritos que tenho como professor universitário e pesquisador (os deméritos, esses são todos de minha responsabilidade). Tento, na medida do possível, reproduzir, nas relaçóes que estabeleço com meus alunos e com meus orientandos, um pouco da dinâmica que ela estabeleceu comigo. Se consigo ou não, essa é outra questão... Hoje, quase vinte anos depois do nosso primeiro encontro, quando surge alguma dúvida sobre o que fazer no meu cotidiano profissional, pergunto-me: "o que a Rita faria?". E se não encontro a resposta, ligo para ela, conversamos longamente ao telefone, e a dúvida se desfaz quase que por encantamento.

Foi Rita quem me ensinou toda a verdadeira extensão do mais importante motto feminista, o pessoal é político: o pessoal é político na medida em que todas as escolhas pessoais que fazemos possuem uma dimensão política e interferem politicamente no mundo e nas relaçôes com os outros que estão ao nosso redor. Muito mais do que minhas leituras de filósofos como Martin Buber, Émmanuel Lévinas e Jacques Derrida, foi a pedagogia do exemplo, a pedagogia do seu exemplo que me ensinou a real dimensão da alteridade como um dos pilares de ação no mundo. Para além das minhas leituras da filosofia de Judith Butler, foi a prática diária de Rita como docente e pesquisadora que me fez incorporar a questáo ética como princípio basilar do meu trabalho intelectual e das minhas práticas cotidianas. Já não era sem tempo que a FAPERGS, no ano de 2015, reconhecesse a sua trajetória e as suas contribuiçóes para o avanço da ciência gaúcha no campo das Artes e das Letras, outorgando-lhe o Prêmio Pesquisador Gaúcho - destaque na modalidade Artes e Letras. Quase dois anos já se passaram desde a premiação, mas o legado de Rita Schmidt que efetivamente me interessa é de ordem diversa. O valor da escuta, da alteridade e da ética como princípios fundamentais - estruturais e estruturantes - tanto do trabalho intelectual quanto das práticas interpessoais cotidianas constituem a herança que dela recebi e que permeia as memórias que dela manterei ao longo de toda a minha vida. 